\title{
Armazenamento de sementes e concentrações de ágar no cultivo in vitro de Brassavola tuberculata Hook. (Orchidaceae)
}

\author{
Gisele Garcia de Sousa' ${ }^{1}$, Benedita Maria Rodrigues Otubo² (i), José Carlos Sorgato3,* (D), \\ Jackeline Schultz Soares ${ }^{3}$ (D), Luan Marlon Ribeiro ${ }^{3}$
}

\author{
Agência Estadual de Defesa Sanitária Animal e Vegetal, Av. Senador Filinto Muller, 1146, CEP 79074-902, Campo Grande, MS, Brasil. \\ ${ }^{2}$ Agência Estadual de Desenvolvimento Agrário e Extensão Rural, Av. Desembargador José Nunes da Cunha, \\ S/N, Bloco 12, CEP 79031-310, Campo Grande, MS, Brasil \\ ${ }^{3}$ Universidade Federal da Grande Dourados, Faculdade de Ciências Agrárias, Unidade II، \\ Rodovia Dourados/Itahum, Km 12, CEP 79804-970, Dourados, MS, Brasil. \\ *josesorgato@ufgd.edu.br
}

Recebido em 13.1I.2019

Aceito em 16.VI.2020

DOI 10.21826/2446-82312020v75e2020017

RESUMO - A semeadura in vitro e a formação de bancos de sementes contribuem para a conservação da variabilidade genética das orquídeas. Objetivou-se avaliar o tempo de armazenamento e as concentrações de ágar na germinação in vitro de Brassavola tuberculata Hook. Foram utilizadas sementes dessecadas por 14 dias e armazenadas por $0,30,60$ e 90 dias a $4 \pm 2{ }^{\circ} \mathrm{C}$. O meio de cultivo MS $1 / 2$ foi utilizado, suplementado com ágar $\left(0 ; 1 ; 2 ; 3 ; 4 ; 5 ; 6 ; 7\right.$ ou $\left.8 \mathrm{~g} \mathrm{~L}^{-1}\right)$. Aos 30 dias após a semeadura foi avaliada a porcentagem de germinação, sendo os dados submetidos a análise de variância. As sementes de $B$. tuberculata germinaram em todas as concentrações de ágar e períodos de armazenamentos avaliados, apresentando germinação média acima de $70 \%$. A porcentagem de germinação diminui com o aumento do período de armazenamento e das concentrações de ágar. Assim, recomenda-se para a semeadura in vitro dessa espécie, sementes armazenadas por até 30 dias, independente da concentração de ágar utilizada no meio de cultura.

Palavras-chave: agente geleificante, conservação de espécies, orquídeas nativas.

\begin{abstract}
Seed storage and agar concentrations on Brassavola tuberculata Hook. (Orchidaceae) in vitro culture. In vitro sowing and seed banks contributes to the conservation of the genetic variability of the orchids. Aimed to evaluate the storage time and agar concentrations on the $i n$ vitro germination of Brassavola tuberculata Hook. Seed samples were dried for 14 days and stored for $0,30,60$ and 90 days under $4 \pm 2{ }^{\circ} \mathrm{C}$. The culture medium was $1 / 2 \mathrm{MS}$, supplemented with agar $\left(0 ; 1 ; 2 ; 3 ; 4 ; 5 ; 6 ; 7\right.$ or $\left.8 \mathrm{~g} \mathrm{~L}^{-1}\right)$. At 30 days after sowing the germination percentage was evaluated and the data were submitted for analysis of variance. The $B$. tuberculata seeds germinated at all concentrations of agar and storage periods evaluated, presenting average germination above $70 \%$. Germination percentage decreases with increasing storage period and agar concentrations. Thus, for in vitro sowing of this species, seeds stored for up to 30 days are recommended, regardless of the agar concentration used in the culture medium.
\end{abstract}

Keywords: gelling agent, species conservation, native orchids.

\section{INTRODUÇÃO}

As espécies de Orchidaceae nativas do Brasil são visadas não apenas por colecionadores, mas também por melhoristas (Cardoso 2017). No país, Barros et al. (2019) listam, no projeto Flora do Brasil 2020 em construção, 2.443 espécies nativas, distribuídas em 207 gêneros, das quais 1.571 são endêmicas, possuindo espécies com potencial econômico, medicinal e ornamental pouco explorados. Dentre estas, destaca-se Brassavola tuberculata Hook, de hábito epifítico, encontrada nos biomas Mata Atlântica, Cerrado e Caatinga, em todos os estados das regiões Sul, Sudeste e Centro-Oeste e alguns estados nas regiões Norte e Nordeste (Barros et al. 2019) Esta espécie é unifoliada, apresentando folhas e caule teretes, cespitosa, que crescem formando densas touceiras com inflorescências que podem ter duas a seis flores agrupadas e perfumadas, de coloração creme a verde-claro, com sépalas e pétalas longolancecoladas e labelo largo, com extremidade pontiaguda. Esse conjunto de características é responsável pelo seu potencial ornamental (Silva et al. 2015).

Na natureza as orquídeas dependem da interação entre fatores bióticos e abióticos, que atuam em seu crescimento, desenvolvimento e sucesso reprodutivo, determinando sua sobrevivência. Nessas condições, ações antropogênicas limitam e reduzem a distribuição e a abundância dessas espécies, por meio da coleta de plantas ou alteração ambiental, resultando na vulnerabilidade dessa família botânica (Fajardo et al. 2017, Gale et al. 2018). Para a conservação destas espécies, a proteção in situ deve ser associada a métodos de conservação ex situ (Yang et al. 2017), tais como a propagação de plantas e a formação de bancos de sementes (Dowling \& Jusaitis 2012, Seaton et al. 2018). 
A germinação assimbiótica tem se mostrado eficiente para propagação de Orchidaceae, pois resulta em maiores porcentagens de germinação, em relação a condições naturais (Abrão et al. 2014, Yang et al. 2017). O meio de Murashige \& Skoog (1962), conhecido como MS, é um dos mais utilizados nesse tipo de cultivo (Vudala \& Ribas 2017) e, dependendo da espécie, pode ser utilizado polimerizado ou líquido. Em meio polimerizado, o ágar tem sido empregado pela sua eficiência como agente geleificante, dando suporte ao crescimento e desenvolvimento in vitro de plantas. Apesar das vantagens apresentadas, é necessário o estabelecimento de concentrações nos meios de cultivo que possibilitem elevados percentuais germinativos e o desenvolvimento satisfatório das plântulas de cada espécie (Faria et al. 2012).

Ainda, o armazenamento de sementes de espécies nativas constitui uma importante ferramenta para evitar a perda de recursos genéticos, de modo a garantir a preservação da diversidade dessa família de plantas especialmente ameaçadas. Um fator essencial para a formação de um banco de sementes de orquídeas é a manutenção da viabilidade das sementes armazenadas, que podem ser utilizadas para a propagação e conservação das espécies, uma vez que, mesmo armazenadas em condições favoráveis, podem ter a viabilidade afetada (Hosomi 2017).

No entanto, para $B$. tuberculata, ainda são poucos os estudos sobre $\mathrm{o}$ armazenamento de sementes e a germinação in vitro, tanto visando a conservação quanto a horticultura. Em vista do exposto, objetivou-se com este trabalho, avaliar o armazenamento de sementes e as concentrações de ágar na germinação in vitro de $B$. tuberculata.

\section{MATERIAL E MÉTODOS}

Foram utilizados como material de estudo, frutos maduros, ainda fechados, oriundos de autopolinização manual de Brassavola tuberculata, provenientes de matrizes com dez anos. Essas foram cultivadas em vasos plásticos número 10 , providos de furos na base para drenagem do substrato, sendo seu volume preenchido com fibra de coco (Golden-Mix Chips, Amafibra). Sendo mantidas em viveiro telado, coberto pela sobreposição de duas telas de sombreamento de $50 \%$ (radiação fotossintética média $=235$ $\mu \mathrm{mol} \mathrm{m}{ }^{-2} \mathrm{~s}^{-1} / 12 \mathrm{~h} / \mathrm{dia}$ ), sob condições médias de temperatura e umidade relativa de $22,6 \pm 5{ }^{\circ} \mathrm{C}$ e $73,9 \pm 10 \%$ e provido de irrigação por micro aspersão, constituído de difusores, posicionados um metro acima das plantas, acionados automaticamente por temporizador digital, sendo realizadas irrigações diárias, que totalizaram uma lâmina de água de $1 \mathrm{~mm} \mathrm{dia}^{-1}$. Quinzenalmente foram realizadas adubações, via foliar, com $2 \mathrm{~mL} \mathrm{~L}^{-1}$ de NPK 10-10-10, acrescido dos micronutrientes: $0,025 \%$ de magnésio, $0,02 \%$ de boro, $0,05 \%$ de cobre, $0,10 \%$ de ferro, $0,05 \%$ de manganês, $0,0005 \%$ de molibdênio e $0,05 \%$ de zinco, com teor máximo de cloro de $0,025 \%$. Para controle fitossanitário, as matrizes foram pulverizadas, preventivamente, com O-Sdimetil-N-acetil-fosforoamidotioato $\left(4 \mathrm{mg} \mathrm{L}^{-1}\right)$ e Mancozeb
(4 mg L $\mathrm{L}^{-1}$ ). Tanto para a adubação foliar, quanto para o controle fitossanitário, foi utilizado pulverizador costal com capacidade para $5 \mathrm{~L}$.

Cinco frutos foram colhidos aos 210 dias após sua formação (Rosa et al. 2013, Macedo et al. 2014) e levados para o Laboratório de Cultivo in vitro, onde foram lavados com água corrente e, na sequência, alocados em Béquer com capacidade para $500 \mathrm{~mL}$ e desinfestados com 300 $\mathrm{mL}$ de álcool (70\%) por cinco minutos, para minimizar a possível contaminação. A seguir, os frutos desinfestados foram abertos com auxílio de bisturi e as sementes foram removidas e homogeneizadas. Em seguida foram pesadas em balança de precisão três amostras de $0,005 \mathrm{~g}$ cada colocadas em tubos de ensaio recebendo $3 \mathrm{~mL}$ de solução aquosa de cloreto de trifenil tetrazólio $0,5 \%$, conforme metodologia proposta por Soares et al. (2014).

Os três tubos de ensaio com as suspensões de sementes foram acondicionados em ambiente desprovido de luz, a $25 \pm 2{ }^{\circ} \mathrm{C}$ por 24 horas. A seguir foram acrescidos de $7 \mathrm{~mL}$ de água destilada e agitados por 1 minuto. Depois, foi pipetado $1 \mathrm{~mL}$ dessa suspensão em câmara de Peters para identificação de sementes viáveis, com o auxílio de um microscópio estereoscópico binocular. Foram consideradas viáveis apenas as sementes com embriões totalmente coloridos de carmim, enquanto que as sementes com embriões incolores, parcialmente corados ou desprovidas de embrião foram consideradas inviáveis Soares et al. (2014).

Após identificação da viabilidade, as sementes provenientes dos cinco frutos, que não foram submetidas ao teste de tetrazólio, foram divididas em quatro porções de igual peso $(0,5 \mathrm{~g})$ e transferidas para dessecador provido de sílica gel por 14 dias. Na sequência, uma dessas quatro amostras foi utilizada para a semeadura in vitro, correspondendo ao tempo de armazenamento de 0 dias [TA(0)], e as outras três foram embaladas individualmente em papel alumínio e colocadas em frascos de polipropileno opaco, com tampa rosqueável, providos de sílica gel, e mantidos sob refrigeração a $4 \pm 2{ }^{\circ} \mathrm{C}$, por 30 [TA(30)], 60 [TA(60)] e 90 dias [TA(90)].

Para a semeadura in vitro, foram utilizadas $0,02 \mathrm{~g}$ de sementes de cada tempo de armazenamento que, em fluxo laminar, foram embebidas em água destilada estéril por 15 minutos em Béquer. Na sequência, a água de embebição foi descartada e as sementes foram desinfestadas por 15 minutos com uma solução de hipoclorito de sódio $(0,8 \%)$, recebendo a seguir, tríplice lavagem com água destilada estéril (50 $\mathrm{mL}$ por lavagem). Após o descarte da água de lavagem o volume da solução foi completado para $120 \mathrm{~mL}$ com água destilada estéril, para a realização da semeadura in vitro.

O meio de cultura utilizado foi Murashige \& Skoog (1962), com metade da concentração dos macro e micronutrientes (MS 1/2), suplementado com $30 \mathrm{~g} \mathrm{~L}^{-1}$ de sacarose e com as concentrações de ágar bacteriológico $\left(1 ; 2 ; 3 ; 4 ; 5 ; 6 ; 7\right.$ ou $\left.8 \mathrm{~g} \mathrm{~L}^{-1}\right)$ ou sem a utilização de ágar (meio líquido - $0 \mathrm{~g} \mathrm{~L}^{-1}$ ), com o $\mathrm{pH}$ ajustado para 5,8 $\pm 0,1$ com $\mathrm{KOH}(1 \mathrm{M})$. Foram utilizados como frascos de cultivo 
recipientes de polipropileno transparentes, providos de tampa, com capacidade para $50 \mathrm{~mL}$, e que após receberem $20 \mathrm{~mL}$ de meio de cultura, foram esterilizados em autoclave a $120^{\circ} \mathrm{C}$ e à pressão de $1 \mathrm{~atm}$, por 20 minutos.

Para cada tempo de armazenamento, após os meios de cultura atingirem a temperatura ambiente, 36 frascos (quatro para cada concentração de ágar testada) foram transferidos para fluxo laminar, e cada um deles recebeu $200 \mu \mathrm{L}$ da suspensão de sementes com auxílio de micropipetador automático estéril. Em seguida, os frascos foram tampados e as culturas acondicionadas em sala de crescimento, com temperatura média $25 \pm 2{ }^{\circ} \mathrm{C}$, fotoperíodo de 16 horas e irradiância de $20,0 \mu \mathrm{mol} \mathrm{m}^{-2} \mathrm{~s}^{-1}$, obtida por meio de duas lâmpadas brancas fluorescentes de $20 \mathrm{~W}$ cada, permanecendo nessas condições por 30 dias.

Decorrido este período, os frascos foram abertos e aqueles contendo meio geleificado, foram acrescidos de $20 \mathrm{~mL}$ de água destilada. Todos foram agitados de forma manual e delicada para formação de suspensão contendo os propágulos, que foi vertida em placa de Petri. Na sequência, com o auxílio de um microscópio estereoscópico binocular com zoom, contou-se o número de embriões clorofilados (EC), número de sementes não germinadas ( $\mathrm{SNG}$ ), sendo a seguir calculada a porcentagem de germinação $(\% \mathrm{G})$ pela expressão: $G=\left(\frac{E C}{S N G}+E C\right) * 100$, modificada de Rosa et al. (2013).

O delineamento experimental utilizado foi inteiramente casualizado, e os tratamentos foram arranjados em esquema de parcelas subdivididas. Foram alocados nas parcelas, os tempos de armazenamento [TA(0); TA(30); TA(60) e $\mathrm{TA}(90)]$ e nas subparcelas as concentrações de ágar $(0 ; 1$; $2 ; 3 ; 4 ; 5 ; 6 ; 7$ ou $8 \mathrm{~g} \mathrm{~L}^{-1}$ ), com quatro repetições de um frasco de cultivo para cada concentração de ágar dentro do mesmo tempo de armazenamento, totalizando 144 frascos de cultivo.

A variável porcentagem de germinação foi transformada por meio da função $\sqrt{ }(\mathrm{x}+1) \mathrm{e}$, a seguir, submetida à análise de variância com auxílio do programa SISVAR (Programa de Análises Estatísticas v.5.3. Universidade Federal de Lavras, MG). Havendo significância, para os fatores estudados foram ajustadas curvas de regressão.

\section{RESULTADOS E DISCUSSÃO}

Houve efeito conjunto do tempo de armazenamento e das concentrações de ágar sobre a porcentagem de germinação (\%G) de Brassavola tuberculata (Fig. 1). Entretanto, só foi observado efeito significativo isolado dos fatores analisados em relação ao tempo de armazenamento.

Quando houve semeadura imediatamente após o período de dessecação [TA(0)], foi observada a maior porcentagem de germinação ( $94 \%$ ), com o valor calculado de 2,9 $\mathrm{g} \mathrm{L}^{-1}$ de ágar, derivado da regressão linear (Fig. 1A), valor este sem diferença estatística do observado para sementes armazenadas por 30 dias [TA(30)] e germinadas em concentração de ágar variando de 0 a $8 \mathrm{~g} \mathrm{~L}^{-1}$ (Fig. 1B).

Sementes armazenadas por 60 dias [TA(60)] apresentaram um decréscimo na $\% \mathrm{G}$ de $11 \%$ em relação àquelas armazenadas por 30 dias (Figs. 1B, 1C) não sendo observado efeito da concentração do ágar nesses resultados. Entretanto, quando as sementes foram armazenadas por 90 dias [TA(90)], a porcentagem de germinação decresceu à medida que a concentração de ágar aumentou, sendo o maior valor $(80,1 \%)$ observado na ausência do geleificante, ou seja em meio líquido (Fig. 1D).

Na conservação de sementes de orquídeas, a umidade e a temperatura das sementes armazenadas interferem nas reações bioquímicas que regulam o metabolismo de cada espécie (Hosomi et al. 2012, Vudala \& Ribas 2017, Seaton et al. 2018). Neste trabalho, de maneira geral, as sementes de $B$. tuberculata apresentaram decréscimo na germinação com o avanço do tempo de armazenamento. Sementes dessecadas por 14 dias e semeadas em seguida [TA(0)], em meio com o valor calculado de $2,9 \mathrm{~g} \mathrm{~L}^{-1} \mathrm{de}$ ágar e aquelas armazenadas por até 30 dias [TA(30)], em todas as concentrações de ágar, apresentaram \%G semelhante. Entretanto, quando armazenadas por até 60 dias, independente das concentrações de ágar, apresentaram germinação $11 \%$ menor e nas armazenadas por até 90 dias as perdas foram de $14,8 \%$, ambas em relação ao [TA(0)].

Hosomi et al. (2012), estudando a conservação de sementes de nove espécies de Cattleya armazenadas a -18 ${ }^{\circ} \mathrm{C}$, observaram que a maioria das espécies apresentaram alta viabilidade aos 35 dias de armazenamento, com germinação variando de $96 \%$ a $99 \%$. Estes resultados corroboram com os encontrados neste trabalho, uma vez que sementes de B. tuberculata quando armazenadas a $4 \pm 2{ }^{\circ} \mathrm{C}$, durante 30 dias também apresentaram elevada germinação (94\%). Indicando que para as espécies estudadas, este período de armazenamento não influenciou na porcentagem de germinação das sementes, independente da temperatura. Esses autores ainda relatam a importância de avaliações periódicas da qualidade das sementes ao longo do tempo, pois apesar da manutenção da viabilidade e da germinação, podem ocorrer mudanças sutis na porcentagem de germinação de algumas espécies, que podem ter implicações no armazenamento ao longo prazo.

Em relação a utilização de ágar, Mweetwa et al. (2008), avaliando a germinação de sementes de Phalaenopsis Sogo Lit-Angel e Phalaenopsis spp. linhagem 9450, armazenadas a $4{ }^{\circ} \mathrm{C}$, também por 30 dias, observaram germinação abaixo de $50 \%$, em meio líquido. Enquanto neste trabalho, para B. tuberculata, a germinação observada foi superior, em torno de $80 \%$.

Embora tenham ocorrido diminuições na $\% \mathrm{G}$ ao decorrer do tempo de armazenamento, estas não foram expressivas, mesmo aos 90 dias, em meios com concentrações mais elevadas de ágar. Esse fato pode indicar que o processo de envelhecimento das sementes não foi acentuado neste tempo de armazenamento, pois em períodos mais prolongados, as reservas de lipídios presentes nas sementes podem estar sujeitas ao processo de peroxidação, um dos eventos mais deletérios, pois causa danos às membranas $\mathrm{e}$ outras macromoléculas (Machado-Neto \& Custódio 2005, Colville et al. 2016). 

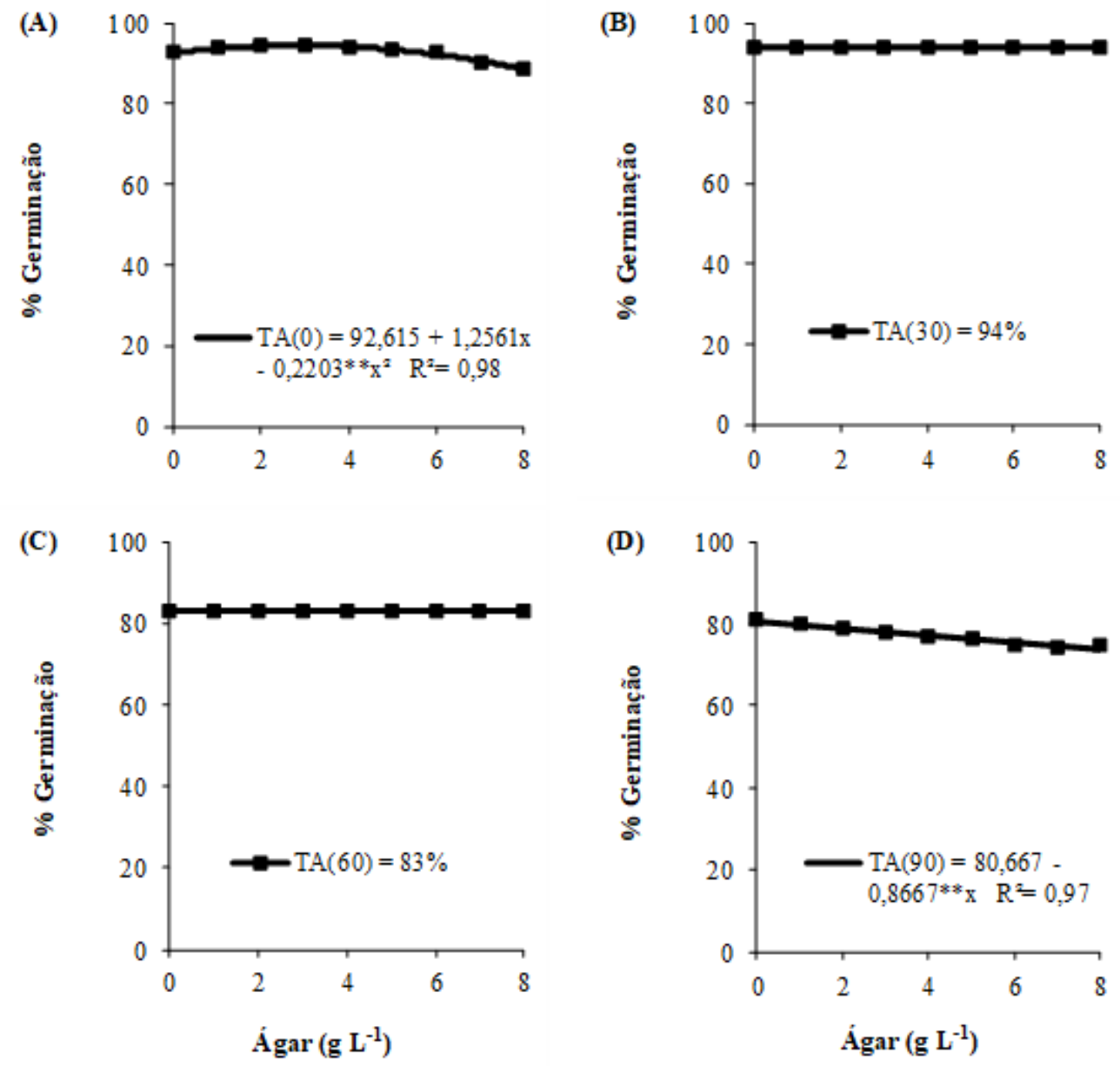

Figs. 1. A-D. Porcentagem de germinação de Brassavola tuberculata Hook. nos tempos de armazenamento (TA). A. zero dias; B. 30 dias; C. 60 dias; D. 90 dias, em função das concentrações de ágar.

Ao analisar cada concentração de ágar dentro do tempo de armazenamento, observou-se que concentrações variando de 0 a $3 \mathrm{~g} \mathrm{~L}^{-1}$ proporcionaram efeitos lineares decrescentes na $\% \mathrm{G}$ à medida que o tempo de armazenamento aumentou. Valores médios, em torno de $96 \%$, foram registrados em $\mathrm{TA}(0)$ e de $80 \%$ para TA $(90)$ nessas concentrações (Figs. $2 \mathrm{~A}, 2 \mathrm{~B}, 2 \mathrm{C}, 2 \mathrm{D})$.

A $\% \mathrm{G}$ de $B$. tuberculata em meios de cultura com concentrações de ágar variando entre 4 e $8 \mathrm{~g} \mathrm{~L}^{-1}$ apresentou comportamento quadrático. As maiores $\% \mathrm{G}$ (média de $94 \%$ ) foram calculadas para o período médio de armazenamento de 11,5 dias. Para essas concentrações de ágar, o armazenamento por 90 dias propiciou $\% \mathrm{G}$ média de $74,4 \%$ (Figs. 2E, 2F, 2G, 2H, 2I), 5\% a menos do que aquelas armazenadas pelo mesmo período, porém cultivadas em meios com concentrações de ágar variando de 0 a $3 \mathrm{~g} \mathrm{~L}^{-1}$ (Figs. 2A, 2B, 2C, 2D).

Houve perdas na $\% \mathrm{G}$ em sementes armazenadas por maior período em função do aumento das concentrações de ágar. Em até $3 \mathrm{~g} \mathrm{~L}^{-1}$ de ágar, as perdas aumentaram com os valores crescentes de ágar e do tempo de armazenamento, enquanto que, para as concentrações mais elevadas de ágar, a maior porcentagem média de germinação (94\%), ocorreu em torno de 11 dias de armazenamento, indicando que meios mais consistentes não favoreceram a germinação das sementes armazenadas.

Deste modo, além da escolha do meio, a sua consistência também deve ser considerada, uma vez que a difusão dos nutrientes para o material vegetal propagado aumenta ou diminui em função da concentração do agente geleificante utilizado (Faria et al. 2012). Possivelmente, neste trabalho, o aumento da concentração de ágar promoveu a elevação do potencial osmótico do meio MS 1/2, dificultando a difusão dos nutrientes para as sementes e consequentemente interferindo na germinação.

A utilização de meio líquido, embora possa favorecer a absorção de nutrientes e minerais, devido à mudança na disponibilidade de substâncias solúveis (Faria et al. 2012), com o aumento das concentrações de ágar não favoreceu a germinação das sementes de $B$. tuberculata armazenadas por 90 dias.

Os resultados deste trabalho indicam que as sementes de $B$. tuberculata armazenadas por até 90 dias, germinaram em todas as concentrações de ágar avaliadas, mesmo em meio com $8 \mathrm{~g} \mathrm{~L}^{-1}$ ágar. No entanto, aquelas armazenadas por períodos superiores a 30 dias tiveram redução na \%G conforme o aumento das concentrações de ágar no meio de cultivo. 

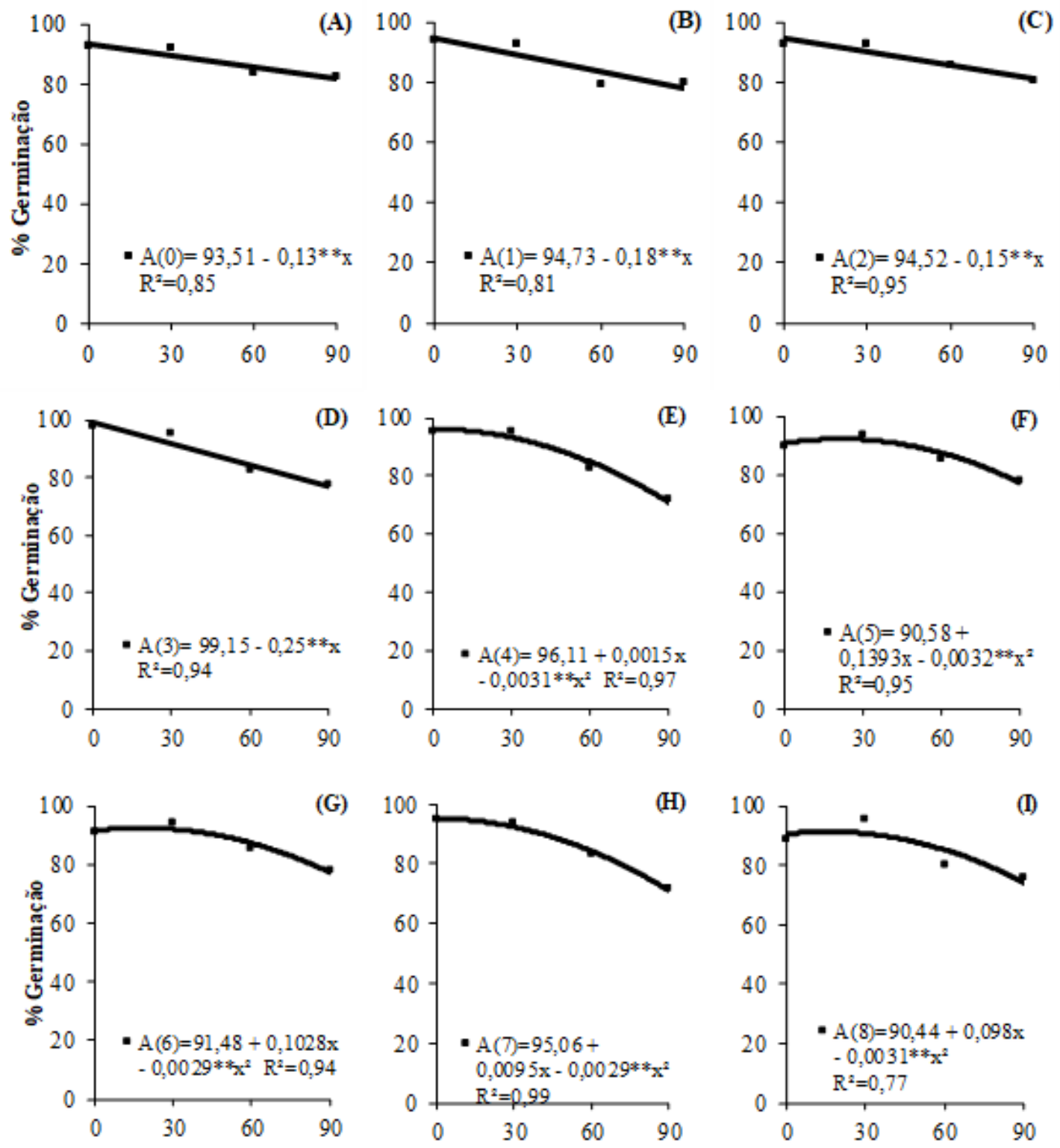

TA (dias)

TA (dias)

TA (dias)

Figs. 2. A-I. Porcentagem de germinação de Brassavola tuberculata Hook. nas concentrações de ágar. A. 0 g L L ; B. 1 g L-1; C. $2 \mathrm{~g} \mathrm{~L}^{-1}$; D. 3 g L-1; E. 4 g L-1 ; F. 5 g L$^{-1}$; G. 6 g L-1; H. 7 g L-1; I. 8 g L-1, em função do tempo de armazenamento (TA).

De acordo com os resultados observados, as sementes de $B$. tuberculata germinaram em todas as concentrações de ágar e períodos de armazenamentos avaliados, apresentando germinação média acima de $70 \%$. Para a semeadura in vitro dessa espécie recomenda-se, sementes armazenadas por até 30 dias, independente da concentração de ágar utilizada no meio de cultura.

\section{REFERÊNCIAS}

Abrão, M.C.R., Jorge, J., Pescador, R., Ferreira, W.M. \& Suzuki, R.M. 2014. Germinação de sementes e desenvolvimento in vitro de plântulas de Cattleya lodigesii Lindl. (Orchidaceae). Revista Brasileira de Biociências 12(3):141-147.
Barros, F., Vinhos, F., Rodrigues, V.T., Barberena, F.F.V.A., Fraga, C.N., Pessoa, E.M., Forster, W., Menini Neto, L., Furtado, S.G., Nardy, C., Azevedo, C.O. \& Guimarães, L.R.S. 2019. Orchidaceae in Flora do Brasil 2020 em construção. Jardim Botânico do Rio de Janeiro. Disponível em: http://floradobrasil.jbrj.gov.br/jabot/floradobrasil/ FB179. Acessado em 16.12.2019.

Cardoso, J.C. 2017. Ionocidium 'cerrado 101': intergeneric orchid hybrid with high quality of blooming. Ornamental Horticulture 23(1):351356.

Colville, L., Marks, T.R., Pritchard, H.W. \& Custodio, C.C. 2016. Development of a reliable GC-MS method for fatty acid profiling using direct transesterification of minimal quantities of microscopic orchid seeds. Seed Science Research 26(1):84-91.

Dowling, N. \& Jusaitis, M. 2012. Asymbiotic in vitro germination and seed quality assessment of Australian terrestrial orchids. Australian Journal of Botany 60(7):592-601. 
Faria, R.T., Assis, A.M., Unemoto, L.K. \& Carvalho, J.F.R.P. 2012. Produção de orquídeas em laboratório. Editora Mecenas, Londrina. $124 \mathrm{p}$.

Fajardo, C.G., Vieira, F.A., Felix, L.P. \& Molina, W.F. 2017. Negligence in the Atlantic forest, northern Brazil: a case study of an endangered orchid. Biodiversity and Conservation 26(5):1047-1063.

Gale, S.W., Fischer, G.A., Cribb, P.J. \& Fay, M.F. 2018. Orchid conservation: bridging the gap between science and practice. Botanical Journal of the Linnean Society 186(4):425-434.

Hosomi, S.T., Custodio, C.C., Seaton, P.T. \& Marks, T.R. 2012. Improved assessment of viability and germination of Cattleya (Orchidaceae) seeds following storage. In Vitro Cellular \& Developmental BiologyPlant 48(1):127-136.

Hosomi, S.T. Sementes de orquídeas: conservação e avaliação de viabilidade. 2017. 157 f. Tese (Doutorado em Agronomia) Universidade do Oeste Paulista, Presidente Prudente, 2017.

Macedo, M.C., Rosa, D.B.C.J., Soares, J.S., Tatara, M.B., Hoffmann, N.T.K., \& Rosa, Y.B. C.J. 2014. Seed storage and acclimatization of Brassavola tuberculata Hook. Semina: Ciências Agrárias 35(6):28832894.

Machado Neto, N.B. \& Custódio, C.C. 2005. Orchid conservation through seed banking: ins and outs. Selbyana 25(2):229-235.

Murashige, T. \& Skoog, F.A. 1962. A revised medium for rapid growth and bioassays with tobacco tissue culture. Physiology Plantarum 15(1):473-497.

Mweetwa, A.M., Welbaum, G.E. \& Tay, D. 2008. Effects of development, temperature, and calcium hypochlorite treatment on in vitro germinability of Phalaenopsis seeds. Scientia Horticulturae 117(3):257-262

Rosa, Y.B.C.J., Júnior, G.A.M., Soares, J.S., Rosa, D.B.C.J., de Macedo, M.C. \& Cezar, A.M. A. 2013. Estudo da viabilidade de sementes de Brassavola tuberculata Hook. em função do período de armazenamento, tempo de cultivo e tratamento pré-germinativo. Ornamental Horticulture 19(2):155-160.

Seaton, P.T., Hosomi, S.T., Custódio, C.C., Marks, T.R., Machado-Neto, N.B. \& Pritchard, H.W. 2018. Orchid seed and pollen: a toolkit for long-term storage, viability assessment and conservation. In Orchid propagation: from laboratories to greenhouses - methods and protocols (Y. Lee \& E.C. Yeung, eds.). Humana press, New York. p. 71-98.

Silva, T.D.S., Felix, L.P., Melo, J.I.M.D. 2015. Bromeliaceae and Orchidaceae on rocky outcrops in the Agreste Mesoregion of the Paraíba State, Brazil. Hoehnea 42(2):345-365.

Soares, J.S., Rosa, Y.B.C.J., Tatara, M.B., Sorgato, J.C. \& Lemes, C.S.R 2014. Identificação da viabilidade de sementes de orquídeas pelo teste de tetrazólio. Semina.: Ciências Agrárias 35(5):2275-2284.

Vudala, S.M. \& Ribas, L.L.F. 2017. Seed storage and asymbiotic germination of Hadrolaelia grandis (Orchidaceae). South African Journal of Botany 108(1):01-07.

Yang, F.S., Sun, A.H., Zhu, J., Downing, X.Q.S. \& Liu, H. 2017. Impacts of host trees and sowing conditions on germination success and a simple ex situ approach to generate symbiotic seedlings of a rare epiphytic orchid endemic to Hainan Island, China. The Botanical Review 83(1):74-86. 